Original Article (full paper)

\title{
Validation of a questionnaire to identify variables that influence the decision-making of setters on different process in Volleyball
}

\author{
Fábio Luis Bordini ${ }^{1,3}\left(\mathbb{0}\right.$, Inara Marques , $^{2,3}$ (1) \\ ${ }^{1}$ Ministério da Defesa, Colégio Militar de Curitiba, Curitiba, PR, Brazil; ${ }^{2}$ Universidade Estadual de Londrina, \\ UEL, Departamento de Educação Física, Centro de Educação Física e Esportes, Londrina, PR, Brazil; ${ }^{3}$ Grupo \\ de Estudos e Pesquisa em Desenvolvimento e Aprendizagem Motora, GEPEDAM, Londrina, PR, Brazil
}

\begin{abstract}
Aim: The present study aimed to construct and validate a questionnaire to identify which information could influence the decision-making process of the setters, according to the functional structure of the volleyball game. Method: The questionnaire had 55 questions, divided into four sections, and was answered by 16 volleyball coaches with an international career (32.8 \pm 5.35 years). The analysis of the results consisted of: (1) descriptive analysis; (2) calculation of agreement between observers; (3) Mode calculation for importance scale; (4) Response index for classification of the information described; (5) Median and interquartile range for the evaluation of the questionnaire. Results: The results indicated that, environmental factors are involved in the decision-making process of the setters and that they influenced, in distinct ways, the decision-making of the setters during the Attack and Counterattack Processes in a volleyball match. Conclusion: Thus, according to the coaches' analysis, the instrument was considered reliable and appropriate for the application and use.
\end{abstract}

Keywords: volleyball, decision making, setters, questionnaire.

\section{Introduction}

Sports modalities, be they individual or collective, are characterized by their dynamicity, in which athletes and teams interact, competing and cooperating with each other, in the unfolding of each game. Consequently, the athletes' Decision-making (DM) process cannot be something static, in which the individuals wait passively for stimuli in order to emit their responses. For Turvey and Shaw ${ }^{1} \mathrm{DM}$ is understood as a complex process, extended in time, and expressed by actions on an ecological scale. Thus, as highlighted by Araújo ${ }^{6}$, more than having all the information about the competition in his or her mind at once, the athlete needs to identify and use whatever information is in the competition itself. However, a recurrent question is how to recognize and identify what information might influence an athlete's DM.

In sports, authors have sought to identify the factors that may restrict or promote athletes' $\mathrm{DM}^{2,7-12}$ and, in volleyball, this interest was aimed to clarify the DM of an athlete in particular: the setter ${ }^{13-17}$. In volleyball, the setter performs a transitional action (cf. ${ }^{18}$ ) and due to its essentiality for the team, is considered by Mesquita and Graça ${ }^{16}$ as the team leader. Specifically, according to Alfonso, Mesquita, Marcelino and Silva ${ }^{14}$, the setter is surrounded by a very large amount of information that can shape his decision and may also present particularities regarding the functional structure of the game. According to Eom and Schutz ${ }^{19}$ this functional structure must be described in "processes", which are initiated in the actions of serving and attacking. Thus, the process initiated by the opposing serve is called the Attack Process (AP) and the one initiated from the opposing team's attack is called the Counter-Attack Process (CAP). However, little is known about what would, in fact, be the most relevant or crucial information influencing the setter's DM, in the different game processes, in deciding for whom to set the ball.

A variety of information has been listed by authors when investigating the DM of the setter and this process of choice goes through different stages, which, in some cases, are not scientifically clear. The main difficulty has been to identify and classify what information, in fact, would provide support to the setter to generate and foster efficient DM. It would, therefore, be of great importance that the opinion of experienced coaches is considered during this process. For such, an interesting instrument to be utilized would be the questionnaire which, according to Günther ${ }^{20}$, has been established as a useful tool to carry out a data collection.

Considering that the collection of informative data on the specification of variables that provide subsidies for DM has been essential in the construction of knowledge regarding the phenomenon, the present study aimed to construct and validate a research instrument in order to identify which variables, could influence the DM of the setters in their process of deciding where to set, according to the functional structure of the game. 


\section{Methods}

\section{Population}

Initially, seventy-five coaches were contacted, of which fortyfive accepted to participate in the study and 32 fulfilled all legal requirements. To standardize the sample, we opted to use only those who show an international career as a coach. Therefore, sixteen volleyball coaches with a mean age of $32.8( \pm 5.35)$ years and an average of $20.75( \pm 8.29)$ years of coaching participated in the study (Table 1). The Informed Consent Form (ICF) was sent by e-mail, and the consent was considered given upon positive response from the recipient. The procedures adopted in this research were in accordance with the Criteria of Ethics in Research with Human Beings, according to Resolution No. 466/12 of the National Health Council, being approved by the Research Ethics Committee (REC) involving Human Subjects of the University local ( $\left.\mathrm{N}^{\circ} 31729114.2 .0000 .5231\right)$.

Table 1: Sample characterization

\begin{tabular}{lccc}
\hline Function & Age* & $\begin{array}{c}\text { Level of competition } \\
\text { in which he worked }\end{array}$ & $\begin{array}{c}\text { Time in } \\
\text { the job* }\end{array}$ \\
\hline Coach & 43,90 & International & 7 \\
Coach & 42,37 & International & 21 \\
Coach & 44,58 & International & 25 \\
Coach & 37,59 & International & 5 \\
Coach & 41,86 & International & 20 \\
Coach & 47,04 & International & 22 \\
Coach & 52,93 & International & 33 \\
Coach & 47,27 & International & 15 \\
Coach & 35,69 & International & 17 \\
Coach & 41,36 & International & 21 \\
Coach & 46,73 & International & 25 \\
Coach & 55,16 & International & 32 \\
Coach & 47,98 & International & 27 \\
Coach & 39,90 & International & 15 \\
Coach & 45,71 & International & 15 \\
Coach & 51,54 & International & 32 \\
\hline
\end{tabular}

Where: *in years. Source: The author

\section{Task}

Participants answered a semi-open electronic questionnaire about possible variables, which could influence the DM process of setters, both in the AP's and in the CAP's.

\section{Instruments: Construction and Structure of the Questionnaire}

The questionnaire was in electronic format, built on the Google Form platform, which provided the online response and direct access to results, besides providing longer reach regarding the better-qualified population, making the acquisition of satisfactory results possible. The questionnaire had 55 questions, which were divided into four sections, described below. The time taken to complete the questionnaire was, approximately, 15 minutes.

\section{Characterization and variables contained in the questionnaire}

The selection of the variables contained in the questionnaire occurred through the reading of specialized books, scientific articles, conversation with coaches and the author's own experience in the sport.

\section{Section 1 - Sample characterization}

This section was composed of eight questions with the objective of characterizing the participant sample of the study.

\section{Section 2 -Attack Process}

In this section, only information concerning the performance of the setters in the AP's was considered. The information referred to the setter's own team, the opposing team, as well as information regarding the ball's trajectory, spatial location and athlete participation. The variables that compose this section were: (1) Last Ball Attacked (LBA): Based on investigations on the phenomenon of " hot hand belief " ( $\mathrm{cf}^{21}{ }^{21}$ ), this variable highlights the possibility of the setter taking into account situations of previous finalizations to decide where to position the ball in an attack condition; (2) Team's Net Composition (TNC): The positioning of the setter in court represents two phases: setter at the front or setter in the back ${ }^{22}$. Thus, in the popular language of the modality, the setter has two nets. The net of two (setter at the front), which consists of the setter and two other attackers (Outside and Middle Hitter) and the net of three (setter in the back), which consists of three attackers (Outside, Middle and Opposite Hitter). Thus, this variable was used to verify if the number of attackers that make up their net is taken into account by the setters, when deciding whom to raise the ball for; (3) Middle-Hitter's Availability (MHA): The attack of mid-net is considered to be the fastest in volleyball, being known as a $1^{\text {st }}$ time attack $^{23}$. This variable verified whether the MHA at the time of ball setting is taken into account in the setter's decision; (4) First Contact Quality (FCQ): The fact that, in volleyball, the rule does not allow the conduction or control of the ball causes an action to have a very large dependence on the quality of the previous action. In this regard, the FCQ (reception) may influence the number of alternatives to the setter's work ${ }^{16,17}$, as well as the results of the attacks ${ }^{24}$. In this sense, this variable questioned whether the setters take into account the FCQ (reception) at the time of making his decision; (5) Setting Zone (SZ): Having a close relationship with the previous variable, the fact that the setter has to move to different places in order to carry out his actions, ends up limiting some possibilities and, consequently, 
enabling others. Thus, this variable served to demonstrate if the setter's decision takes into account the place from where he is performing his action; (6) Setting Technique (ST): Settings with jump give the possibility of organizing faster attacks, of $1^{\text {st }}$ and $2^{\text {nd }}$ time, which, according to Costa, Mesquita, Greco, Ferreira and Moraes $^{23}$, present greater efficiency in scoring. In this way, this variable questioned if the possibility of using varied techniques in the execution of his action is taken into account by the setter in their DM process; (7) Hitters' Availability (HA): As the main function of the setter's actions is to create difficulties for the blocking actions of the opposing team ${ }^{14}$, the greater the number of attackers available for completing an offensive move, the greater the difficulty imposed to the blocking actions of the opposing team. This variable highlighted, then, if the number of attackers available for an offensive move, at the moment of the setter's action, influences his DM; (8) Longest Distance Hitter (LDH): Giving the function of setting as proposed by Alfonso, Mesquita, Marcelino and Silva ${ }^{14}$, which is to cause difficulty in blocking actions, one way would be to increase the distances whose blockers must cover in order to be able to mount more efficient defenses. In this sense, this variable investigated whether the setter takes into account the attacker available at the greatest distance from him, at the moment of deciding whom to set the ball for; (9) Infiltration/Exchange Position (IEP): During matches, for the setter to be able to carry out his actions efficiently, he must infiltrate while in the zone of defense, or perform exchanges while in the attack zone. In this way, such infiltrations/exchanges cause the setter to cover different distances in order to position itself for setting, which may facilitate some settings and hamper others. Thus, this variable had the function of informing if, at the moment of making their decision, the setters take into account the position of where they are infiltrating or making exchanges; (10) Who Made the First Contact (WFC): In high-level volleyball, three team athletes (two Outside Hitters and the libero) are considered the top priority athletes in receiving the serve of the opposing team. Especially in the case of pointers, such accumulated responsibilities can be decisive when the setter decides where to set. Thus, this variable highlighted whether, at the moment of making his decision, the setter takes into account which athlete performed the action of receiving the serve (reception); (11) Reception Zone (RZ): The place where an athlete performs the reception, even if it is of good quality, can affect the movement of the setters in the performance of their actions. Thus, this variable investigated whether the place from which the reception happens affects the DM of the setters in order to decide whom to set the ball for; (12) Set Period (SP): In modalities based on scoring $\left(\mathrm{cf}^{25}\right)$, it is understood that the closer the team is to the target score, the greater the psychological burden placed on the athlete responsible for completing the point. Thus, this variable indicates if, in making his decision, the setter takes into account the SP in which the action happens; (13) Opponent Team's Blocking Tactic - Positioning (OBP): Since the athletes occupy different positions in relation to their positions in court, this variable aimed to verify if, in making their decision, the setters use the information of the initial positioning of each one of the players that may comprise the blocks; (14) Opponent Team's Blocking Tactic - Anticipation (OBA): Together with the previous topic and recalling the two block strategies described by Alfonso, Mesquita, Marcelino and Silva ${ }^{14}$, this variable aimed to identify if the setters use the information of the blocking strategies in order to make their decisions; (15) Blocking Weak Point (BWP): Because of the rotation imposed on teams, the composition of the blocks suffers from the use of players with different characteristics: technically inferior, shorter players, players who jump less, among other things. Thus, this variable describes whether setters take into account the BWP of the opposing team at the time they make their decisions; (16) Opponent Team's Serve Location (OSL): During the serve, players who choose to perform their actions further from the end line, end up taking longer to compose the defensive system of their team. In this sense, this variable was used to evaluate if the place where the athlete of the opposing team performs the serve influences the DM of the setter of the opposing team; (17) Opponent Team's Serve Type (OST): According to Costa, Mesquita, Greco, Ferreira and Moraes ${ }^{23}$, different types of serves are used in volleyball. The purpose of this variable was to identify if the type of serve used by the opposing team influences the action of the setter when deciding which attacker to direct the ball to.

\section{Section 3 - Counterattack Process}

As in the previous section, section 3 also contemplated different types of information. However, in this section, the information represented the setters' performance, exclusively, in CAP's. The information also referred to the setter's own team, the opposing team, as well as information regarding the ball's trajectory, spatial location and athlete participation.

It should be noted that most of the variables listed in the AP were also present in the CAP. Therefore, only the variables with characteristics different from those found in the PAT'S were described. Thus, this section is composed of: (1) LBA; (2) TNC; (3) MHA; (4) FCQ; (5) SZ; (6) ST; (7) HA; (8) LDS; (9) WFC; (10) RZ; (11) SP; (12) OBP; (13) OBA; (14) BWP; (15) Infiltration/Exchange Position (IEP): Differently from what happened in the APs, during the CAPs the setters have a more restricted movement. While in the defense zone, they infiltrate, almost exclusively, from position 1, whereas when located in the attack zone, their exchanges are almost exclusively performed from position 2 . Thus, this variable identified whether, even starting from these two positions, setters take them into account when making their decisions. (16) Blocker Efficiency (BE): Since the rules of the game only allow the three players at the attack zone to block at each rotation, after receiving the ball from an attack, they must be available to the setter in order to compose the offensive play. Thus, this variable evaluated whether or not a damping of the ball by the blockers and/or the net interfere in the setter's 
action decision; (17) Opponent Team's Blocking Tactic Formation (OBF): In CAP, by moving to positions that are farther from their attack positions, some players who are part of the block show difficulties in being well positioned for subsequent attack actions. Because of this, this variable identified whether setters, when making their decisions for whom to set, take into account the players who were part of the blocking composition; (18) Location of Opponent Team's Attack (LOA): During the rallies, there are several options for attackers (positions 1, 2, 3, 4 and 6) to be used by setters. This variable indicates whether, in making his decision, the setter takes into account the position of the opposing court in which the attack was performed. (19) Opponent Team's Attack Type (OAT): Attack actions in volleyball may vary in time and type $\left(\mathrm{cf}^{23}\right)$. Thus, this variable highlighted whether the setter's decision is also based on the type of attack performed by the opposing team.

\section{Section 4 - Evaluation of the questionnaire}

In this section, the objective was to evaluate the proposed instrument. Thus, the variables that composed this section were: (1) Response time: Identified the time used by the participants to answer the questionnaire; (2) Clarity of the questions: Evaluated if the questions that make up the questionnaire were clearly described; (3) Relevance of questions: Indicated the relevance of the variables used to compose the questions of the questionnaire; (4) Accuracy: Indicated whether the questionnaire was able to capture what it was actually built for; (5) Importance of variables: Identified the importance of the variables contained in the questionnaire; (6) Satisfaction: identified the satisfaction of each participant with the proposed tool.

\section{Structure of questions and answers}

In the first section, multiple choice questions were elaborated, in which the participants indicated their answers by pointing out the items of interest, and open questions, in which they indicated, in numbers, the years of performance in the given function. For the second and third sections, each question was divided into two parts. Initially, the participant was asked to answer by stating "yes" or "no" whether the information contemplated in the question would be taken into account by the setter in his DM process, in order to decide where to set. If so, the participant was asked to answer the second part of the question, which referred to the importance given to the information contained to in the first part of the question for the setter's decision-making process. For this second part of the question, a scale of importance from one to three was used, in which one indicated the most important and three, the least important. When the answer to the first part of the question was negative, the participant continued the questionnaire without the need to answer the part concerning the importance of the information.
The second and third sections had two questions each, which were used to complement the information. In these questions, the participants were asked if they believed that there was other information, not included in the instrument that could be relevant to the setter in their DM process. One of the questions was about information coming from the team itself and the other about information coming from the opposing team. If the participants believed that there was other information that could be considered, they could describe it, also indicating its scale of importance. Some information was listed by the participants, being that the highlight is the information coming from the "best attacker at the time of the game". Such information is described in the results of the study.

The questions in the fourth section were constructed on a Likert-type scale, in which the participants selected their level of agreement regarding the contents and structure of the questionnaire. Each question consisted of five staggered options from one to five, in which the value one presented as the worst result and the value five as the best.

\section{Procedures}

Initially, the participants were contacted, either personally or via telephone and/or Internet, and asked about their interest in participating in the study. In this contact the objectives of the study were explained and, to those interested in participating, their electronic address was requested. Subsequently, a message was sent to the participant via email, containing a formal invitation to participate and an attached file containing the consent form.

The consent form was considered read and accepted if the professional responded positively to the email regarding participation in the research. Upon receiving confirmation, a second e-mail was sent to the professional, thanking him for his participation, as well as information and instructions regarding the questionnaire to be answered. The information was related to the steps that should be followed in filling in the instrument, and what should be considered in each of the sections of the questionnaire.

This email also included the participant's code, which should be inserted at the beginning of the questionnaire response process. At the end of the email, the participant found a hyperlink which, upon clicking it, redirected the participant to the questionnaire. Following the instructions in the email and also in each of the questions, the participant answered the questionnaire without any difficulty. At the end of the questionnaire, the participant clicked on the "Send responses" link in order for their data to be sent to the database.

\section{Statistical analysis}

A descriptive analysis of some of the results was performed, referring to the four sections of the questionnaire, using Mean (X) and Standard Deviation $( \pm)$. Reliability and 
validity were verified for each of the items the first part of the questions in sections two and three of the questionnaires, since, for Martins ${ }^{26}$, these two qualities are fundamental for the elaboration of measurement instruments. These assumptions were evaluated through the Interobserver Agreement (IOA) that, according to Thomas, Nelson and Silverman ${ }^{27}$ stipulate an IOA $>0.8$ for an index to be considered strong. For the second part, which highlights the importance of information, the Mode was calculated for each information in order to find the most frequent behavior. After the descriptions of the CEOs and Mode, a Response Index (RI) was elaborated, which considered both values, in order, to obtain a classification of importance for the information described during the AP's and CAP's. The calculation of RI is described in equation 1, below:

$\frac{\left.\mathrm{RI}=\left(\left(\left(\mathrm{IOA}_{\mathrm{g}} \cdot \mathrm{IOA}_{1}\right) \cdot 3\right)+\left(\left(\mathrm{IOA}_{\mathrm{g}} \cdot \mathrm{IOA}_{2}\right) \cdot 2\right)+\left(\left(\mathrm{IOA}_{\mathrm{g}} \cdot \mathrm{IOA}_{3}\right) \cdot 1\right)\right) \cdot 100\right)}{3}$

Where IOA $_{g}$ corresponds to general IOA; IOA corresponds to the number of participants who identified the information as of first importance; IOA $_{2}$ corresponds to the number of participants who identified the information as of secondary importance; $\mathrm{IOA}_{3}$ corresponds to the number of participants who identified the information as of third importance.

In the fourth section, which was responsible for evaluating the questionnaire, a Median calculation was performed for each of the highlighted items, together with the values of the first and third quartiles and maximum and minimum values.

\section{Results}

First, the values of IOA, Mode, and RI referring to the analysis of the AP's are presented, followed by the values referring to the analysis of th e CAP's, as well as the Median values found in the evaluation of the questionnaire by the technicians.

\section{Attack Processes}

In the AP's it was verified that $82.35 \%$ of the sources of information contained in the questions presented an IOA $>0.8$. The IOA's values, for each of the information contained in the questionnaire, are shown in figure 1.

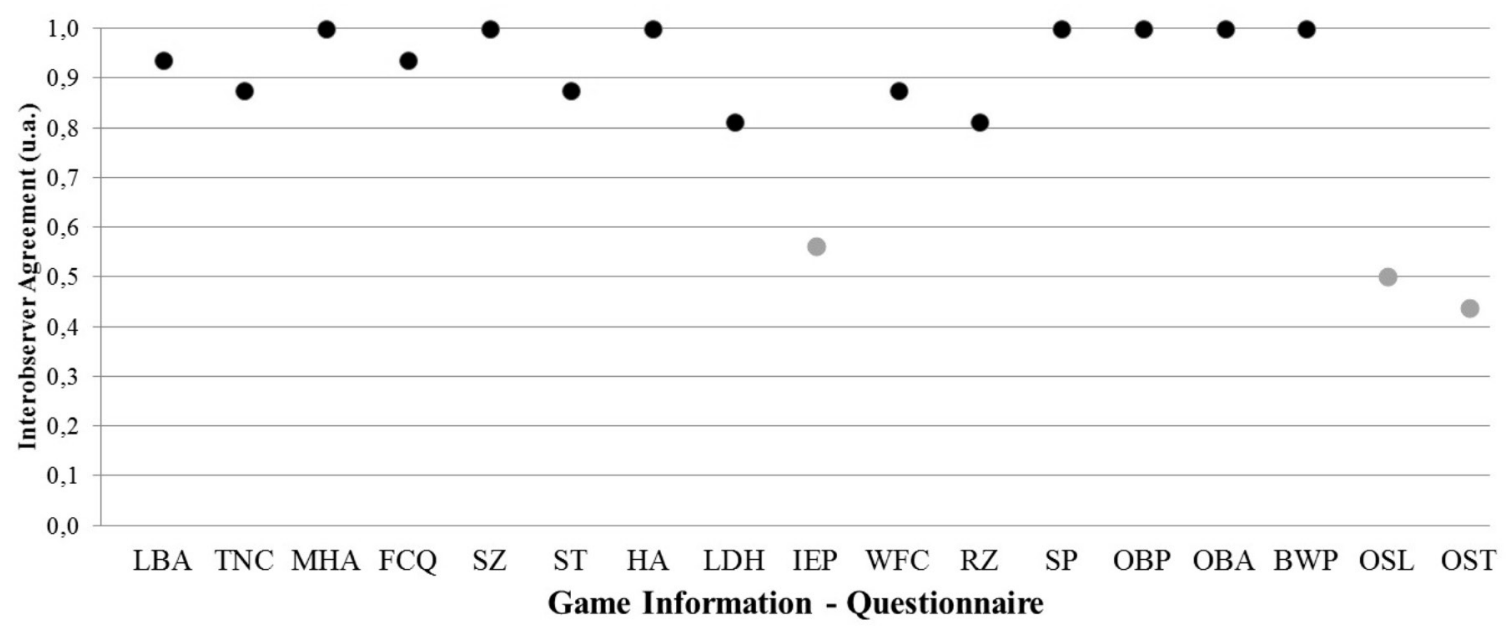

Figure 1: Interobserver Agreement values of each of the game information encountered by the setters during the Attack Processes, contained in the questionnaire.

Where: Last Ball Attacked (LBA); Team's Net Composition (TNC); Middle-Hitter's Availability (MHA); First Contact Quality - Pass (FCQ); Setting Zone (SZ); Setting Technique (ST); Hitters' Availability (HA); Longest Distance Hitter (LDH); Infiltration/Exchange Position (IEP); Who Made the First Contact - Pass (WFC); Reception Zone - pass (RZ); Set Period (SP); Opponent Team's Blocking Tactic - Positioning (OBP); Opponent Team's Blocking Tactic - Anticipation (OBA); Blocking Weak Point (BWP); Opponent Team's Serve Location (OSL); Opponent Team's Serve Type (OST). Source: The author

Thus, according to the participants, the information that most influences the DM process of the setter $(\mathrm{IOA}=1)$ concerns MHA, SZ, HA, SP, OBP, OBA and BWP. These were followed by information from LBA and FCQ $(\mathrm{IOA}=0.94)$. Information on TNC, ST and WMC followed with $\mathrm{IOA}=0.88 . \mathrm{LDH}$ and $\mathrm{RZ}$ obtained IOA $=0.81$. The information contained in the questionnaire that, in the opinion of the coaches, fewer influences the DM process of the setters refers to the IEP occupied by the setter at the beginning of the AP's $(\mathrm{IOA}=0.56)$, the OSL $(\mathrm{IOA}=0.5)$ and the OST $(\mathrm{IOA}=0.44)$.

For the second part of the same 17 questions, the Mode was calculated considering the scale of importance given to each of the information contained in the questionnaire, in order to identify the most frequent importance value. The Mode values of each of the information contained in the questionnaire are presented in figure 2 . 


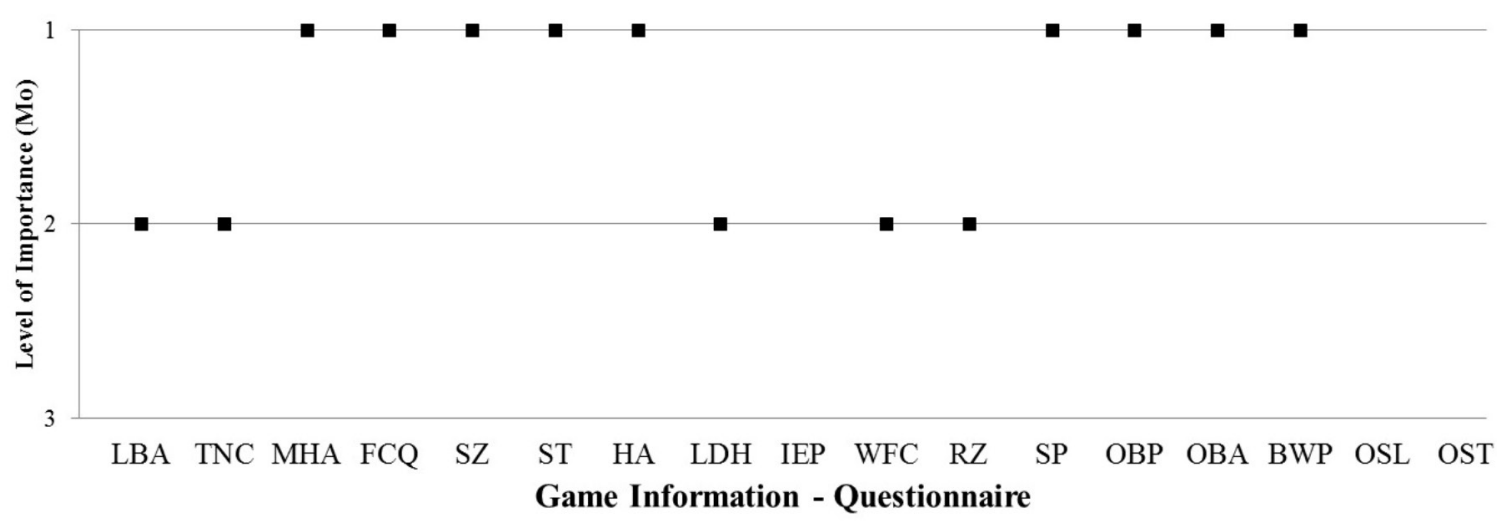

Figure 2: Mode values of each of the game information faced by the setters during the Attack Processes contained in the questionnaire. Where: Last Ball Attacked (LBA); Team's Net Composition (TNC); Middle-Hitter's Availability (MHA); First Contact Quality - Pass (FCQ); Setting Zone (SZ); Setting Technique (ST); Hitters'Availability (HA); Longest Distance Hitter (LDH); Infiltration/Exchange Position (IEP); Who Made the First Contact - Pass (WFC); Reception Zone - pass (RZ); Set Period (SP); Opponent Team's Blocking Tactic - Positioning (OBP); Opponent Team's Blocking Tactic - Anticipation (OBA); Blocking Weak Point (BWP); Opponent Team's Serve Location (OSL); Opponent Team's Serve Type (OST). Source: The author.

The Mode showed that $52.94 \%$ of game information was classified by coaches as first order information $(\mathrm{Mo}=3)$ for setters. These would be the information that most directly influences the DM process of the setters during the AP's. It was also verified that $29.41 \%$ of game information was classified as second-order information $(\mathrm{Mo}=2)$. Although this information would influence the setters DM process, it would be at a second level of importance. It is important to highlight that, according to the coaches, no information was classified as third-order information, and that three of the information $(17.65 \%)$ would not influence the DM process of the setter, and thus, are not shown in figure 5 .

In order to classify the information regarding the importance given to it by the coaches, an RI was elaborated. This index took into account the values of IOA, as well as the values of the importance scale given by the participants. In this sense, a classification of importance was created for the information contained in the PATs, which is presented in table 2.

Table 2: Classification of information contained in the Attack Processes based on their Response Index.

\begin{tabular}{clc}
\hline Ranking & \multicolumn{1}{c}{ Information } & RI \\
\hline $1^{\text {st }}$ & Hitters' Availability & 97.92 \\
$2^{\text {nd }}$ & Opponent Team's Blocking Tactics - Positioning & 97.92 \\
$3^{\text {rd }}$ & Opponent Team's Blocking Tactics - Anticipation & 95.83 \\
$4^{\text {th }}$ & Blocking Weak Point & 93.75 \\
$5^{\text {th }}$ & Middle-Hitter's Availability & 91.67 \\
$6^{\text {th }}$ & Setting Zone & 85.42 \\
$7^{\text {th }}$ & Set Period & 81.25 \\
$8^{\text {th }}$ & Last Ball Attacked & 70.31 \\
\hline
\end{tabular}

(To be continued)
Table 2: Classification of information contained in the Attack Processes based on their Response Index.

\begin{tabular}{clc}
\hline Ranking & \multicolumn{1}{c}{ Information } & RI \\
\hline $9^{\text {th }}$ & Setting Technique & 69.27 \\
$10^{\text {th }}$ & First Contact Quality - pass & 60.55 \\
$11^{\text {th }}$ & Team's Net Composition & 60.16 \\
$12^{\text {th }}$ & Reception Zone - pass & 44.01 \\
$13^{\text {th }}$ & Who Made the First Contact - pass & 41.93 \\
$14^{\text {th }}$ & Longest Distance Hitter & 40.63 \\
$15^{\text {th }}$ & Infiltration/Exchange Position & 17.58 \\
$16^{\text {th }}$ & Opponent Team's Serve Location & 15.63 \\
$17^{\text {th }}$ & Opponent Team's Serve Type & 13.67 \\
\hline
\end{tabular}

Where: (RI) Response Index. Source: The author

With regard to the two questions that aimed to complement the information contained in the questionnaire, the first one referred to information from the setter's own team and the second to information about the opposing team. According to the result of the questionnaire, $62.5 \%$ of the coaches described complementary information regarding the setter's own team, which they considered important for the DM process of the setters during the AP's. However, for the most part, the information pointed out by the coaches as complementary were related to some of the information already contained in the questionnaire. Thus, for better visualization, the complementary information was synthesized in Table 3, together with the information, already contained in the composition of the questionnaire, which related to the information described by the coaches. Complementary information that did not show any related information among those composing the questionnaire was identified as "Not included". 
Table 3: List of information related to the setter's own team complemented by the coaches with the information contemplated in the questionnaire during the Attack Processes.

\begin{tabular}{cc}
\hline Information of the Team & Related Information \\
\hline Psychological situation of players & Set Period \\
Attacker's Approach to fit the & $\begin{array}{c}\text { Who, Quality and Zone of } \\
\text { Falls }\end{array}$ \\
$\begin{array}{c}\text { First Contact and Hitter's } \\
\text { Availability }\end{array}$ \\
Technical data from video & All Information \\
Best Hitter & Not Included \\
Game Score & Survey Site Set Period \\
Hitter in the shortest distance & Not included \\
Statistical data during matches & All Information \\
Availability of player to receive & Who, Quality and Zone of \\
the lifted ball & First Contact and Hitter's \\
\end{tabular}

Source: The author

With regard to information of the opposing team, 37.5\% of coaches offered complementary information. This information was summarized and is contained in Table 4, along with its relationship, if existing, with the information contained in the questionnaire composition.
Table 4: List of information related to the opposing team complemented by the coaches with the information included in the questionnaire during the Attack Processes.

\begin{tabular}{cc}
\hline Opponent Team Information & Related Information \\
\hline Placement of the central blocker & Opponent Team's Blocking \\
in relation to the central striker & Tactics - Positioning \\
Positioning of defense players & Not included \\
Opponent's block quality & Blocking Weak Point \\
Substitution in the opposing team & All Information \\
Opponent blocking technique & Not included \\
Anticipation of middle & Opponent Team's Blocking \\
Previous matches (in the game & Tactic - Anticipation \\
and in other matches) & All Information \\
\hline
\end{tabular}

Source: The author

\section{Counterattack Process}

Differently from the analysis of APs, for the CAPs it was verified that only $63.16 \%$ of the sources of information contained in the questions have shown an IOA $>0.8$. The IOA's values for each of the information contained in the questionnaire are described in figure 3 .

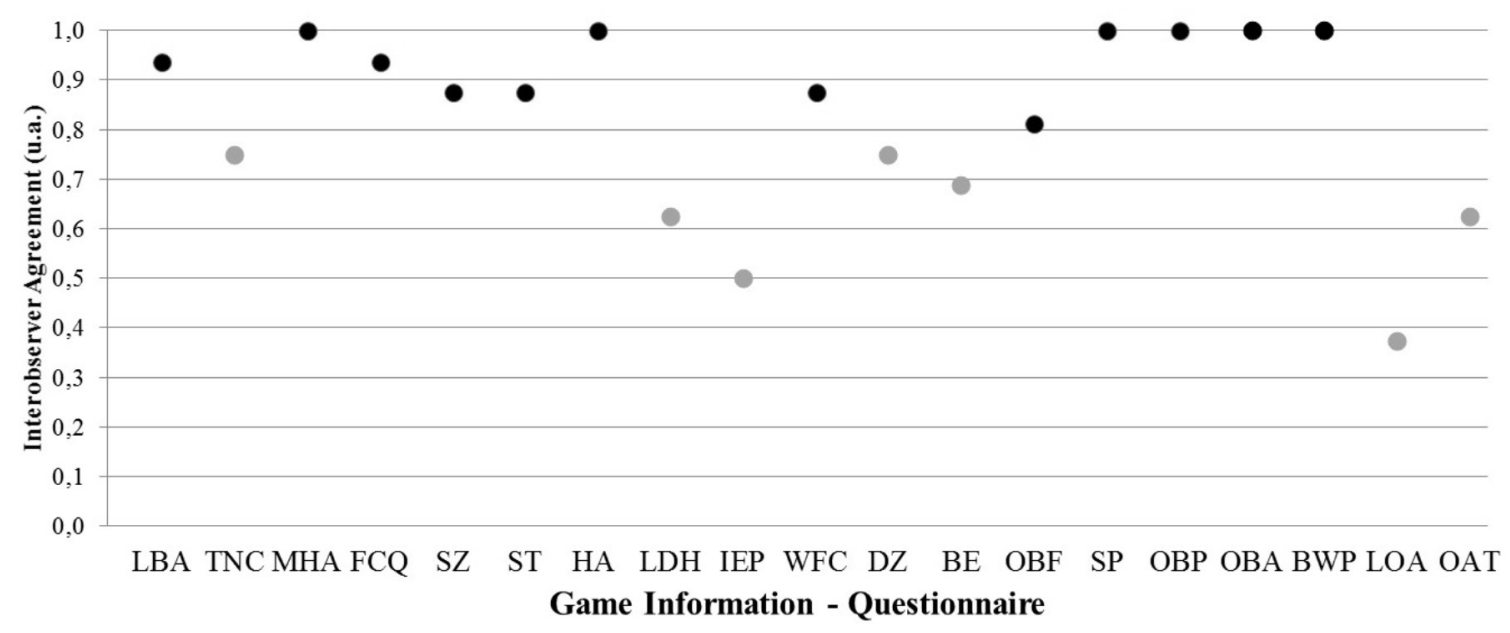

Figure 3: Interobserver Agreement values of each of the game information encountered by the setters during the Counter Attack Processes contained in the questionnaire.

Where: Last Ball Attacked (LBA); Team's Net Composition (TNC); Middle-Hitter's Availability (MHA); First Contact Quality - defense (FCQ); Setting Zone (SZ); Setting Technique (ST); Hitters' Availability (HA); Longest Distance Hitter (LDH); Infiltration/Exchange Position (IEP); Who Made First Contact - Defense (WFC); -Defense Zone (DZ); Blocker Efficiency (BE); Opponent Team's Blocking Tactic - Formation (OBF); Set Period (SP); Opponent Team's Blocking Tactic Positioning (OBP); Opponent Team's Blocking Tactic - Anticipation (OBA); Blocking Weak Point (BWP); Location of Opponent Team's Attack (LOA); Opponent Team's Attack Type (OAT). Source: The author

From these results, it was verified that the information that influences the DM process of setters during the CAPs resemble those pointed by coaches regarding the AP's. Thus, according to the participating coaches, it was verified that the information that most influences the DM process of the setter during the CAP's are related to the MHA, HA, SZ, OBP, OBA and BWP, all showing $\mathrm{IOA}=1$. This main information was also followed by information from the results of the LBA and FCQ $(\mathrm{IOA}=0.94)$. Information on SZ, ST and WMC followed, with $\mathrm{IOA}=0.88$.
$\mathrm{TNC}$ and $\mathrm{DZ}$, with $\mathrm{IOA}=0.75$, followed by $\mathrm{BE}$, with $\mathrm{IOA}=0.69$. Next, with $\mathrm{IOA}=0.63$, came the information pertaining to $\mathrm{LDH}$ and OAT. The information contained in the questionnaire that, in the opinion of the coaches, less influence the process of DM of the setters were IEP $(\mathrm{IOA}=0.5)$ and LOA $(\mathrm{IOA}=0.38)$.

For the second part of the questions, the same procedure performed for the AP was carried out. Thus, the Mode values of each of the information contained in the questionnaire are presented in figure 4. 


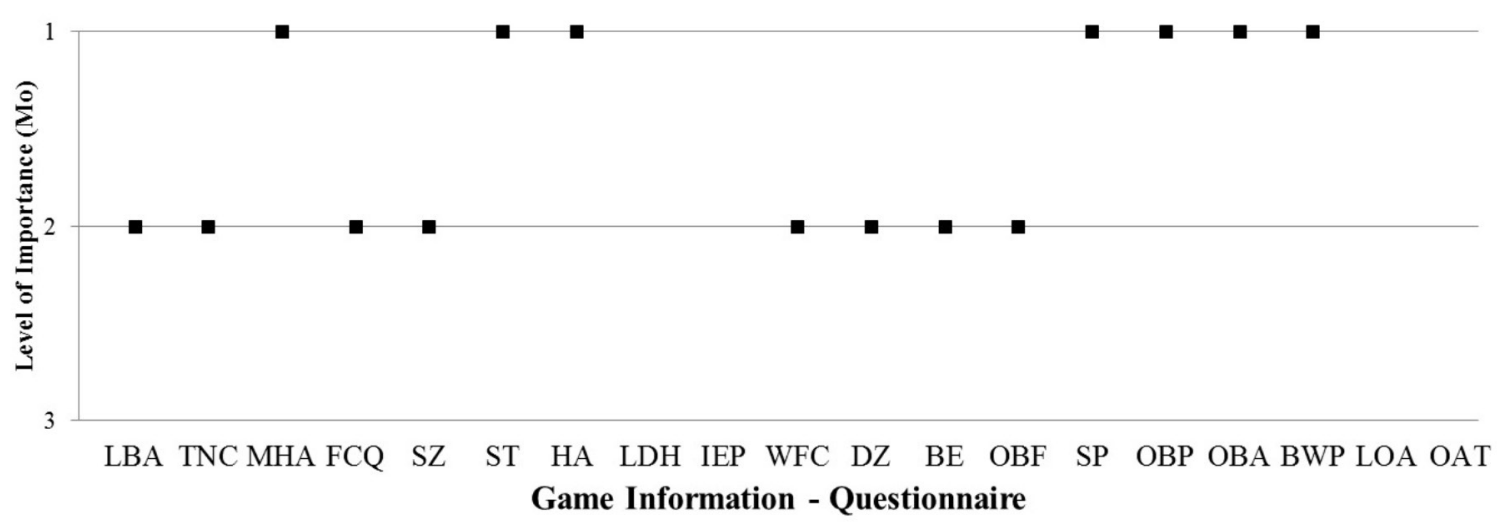

Figure 4: Mode values of each of the game information encountered by the setters during the Counter Attack Processes contained in the questionnaire.

Where: Last Ball Attacked (LBA); Team's Net Composition (TNC); Middle-Hitter's Availability (MHA); First Contact Quality - defense (FCQ); Setting Zone (SZ); Setting Technique (ST); Hitters' Availability (HA); Longest Distance Hitter (LDH); Infiltration/Exchange Position (IEP); Who Made First Contact - Defense (WFC); -Defense Zone (DZ); Blocker Efficiency (BE); Opponent Team's Blocking Tactic - Formation (OBF); Set Period (SP); Opponent Team's Blocking Tactic Positioning (OBP); Opponent Team's Blocking Tactic - Anticipation (OBA); Blocking Weak Point (BWP); Location of Opponent Team's Attack (LOA); Opponent Team's Attack Type (OAT). Source: The author

The results showed that, unlike the APs, only $36.84 \%$ of the game information was classified by the coaches as first order information $(\mathrm{Mo}=3)$ for the setters. This information could influence more directly the DM process of the setters during the CAP's. It was also verified that $42.11 \%$ of the game information was classified as second-order information. This information would influence the DM process of the setters; however, they would be at the second level of importance. It should be noted that, as in the APs, none of the information was referred to as third-order information, and that $21.05 \%$ of the information, according to the coaches, does not interfere with the DM process of the setters during the CAP's. Thus, they are shown without Mode value.

As in the APs, in order to classify the information regarding the importance given to them by the coaches, the RI was calculated. The classification of importance for the information contained in the CAP's is presented in table 5.

Table 5: Classification of information contained in the Counter-Attack Processes based on the response rate obtained.

\begin{tabular}{clc}
\hline Ranking & \multicolumn{1}{c}{ Information } & RI \\
\hline $1^{\text {st }}$ & Hitters' Availability & 95.83 \\
$2^{\text {nd }}$ & Blocking Weak Point & 89.58 \\
$3^{\text {rd }}$ & Opponent Team's Blocking Tactics - Positioning & 87.50 \\
$4^{\text {th }}$ & Middle-Hitter's Availability & 83.33 \\
$5^{\text {th }}$ & Set Period & 81.25 \\
$6^{\text {th }}$ & Opponent Team's Blocking Tactic - Anticipation & 81.25 \\
$7^{\text {th }}$ & Last Ball Attacked & 70.31 \\
$8^{\text {th }}$ & Setting Technique & 65.63 \\
$9^{\text {th }}$ & First Contact Quality - Defense & 64.45 \\
$10^{\text {th }}$ & Setting Zone & 58.33 \\
$11^{\text {th }}$ & Who Made the First Contact - Defense & 54.69 \\
$12^{\text {th }}$ & Opponent Team's Blocking Technique - Formation & 54.17 \\
\hline
\end{tabular}

(To be continued)
Table 5: Classification of information contained in the Counter-Attack Processes based on the response rate obtained.

\begin{tabular}{clc}
\hline Ranking & \multicolumn{1}{c}{ Information } & RI \\
\hline $13^{\text {th }}$ & Team's Net Composition & 46.88 \\
$14^{\text {th }}$ & Defense Zone & 35.94 \\
$15^{\text {th }}$ & Efficiency of Blockers & 35.81 \\
$16^{\text {th }}$ & Opponent Team's Attack Type & 31.25 \\
$17^{\text {th }}$ & Longest Distance Hitter & 28.65 \\
$18^{\text {th }}$ & Infiltration/Exchange Position & 16.67 \\
$19^{\text {th }}$ & Location of Opponent Team's Attack & 11.72 \\
\hline
\end{tabular}

Where: (RI) Response Index. Source: The author

Questions for complementing information have been described as in the AP. According to the result of the questionnaire, $37.5 \%$ of coaches described complementary information, referring to the setter's own team, which they considered important for the DM process of the setter during the CAP's. Such information was summarized in Table 6 , along with the information contained in the questionnaire, if any, which was related to the information described by the coaches.

Table 6: List of information related to the setter's own team complemented by the coaches with the information included in the questionnaire during the Counter-Attack Processes.

\begin{tabular}{cc}
\hline Adversary Team Information & Related Information \\
\hline Best attacker & Not included \\
First Contact Quality & First Contact Quality \\
$\begin{array}{c}\text { Substitution in the opposing team by } \\
\text { moving to positions that are farther } \\
\text { from their attack positions }\end{array}$ & All Information \\
Striker in the shortest distance & Not included \\
Perception of players fatigue in & Who, Quality and Zone of \\
longer rallies & First Contact and Attackers \\
& Availability \\
\hline
\end{tabular}

Source: The author 
With regard to the information of the opposing team, $18.75 \%$ of the coaches supplied complementary information. This information was summarized and is shown in table 7, along with the information contained in the questionnaire, if any, which was related to the information described by the coaches.

Table 7: List of information related to the setter's opposing team complemented by the coaches with the information included in the questionnaire during the Counterattack Processes.

\begin{tabular}{cc}
\hline Opponent Team Information & Related Information \\
\hline Substitution in the opposing team & All Information \\
& Opponent Team's Blocking Tactics \\
Characteristics of the blockers & - Positioning; Opponent Team's \\
& Blocking Tactic - Anticipation; \\
First Contact Quality & Blocking Weak Point \\
\hline
\end{tabular}

Source: The author

\section{Evaluation of the Questionnaire}

According to the analysis of the results, $68.75 \%$ of the participants took between 11 and 20 minutes to answer the questionnaire in its entirety. For $25 \%$, the questionnaire was completed within 10 minutes, and only $6.25 \%$ of the participants needed more than 21 minutes to complete the questionnaire.

For the questions that evaluated the content of the questionnaire, a scale ranging from one (unclear) to five (very clear) was used. For the analysis of the results of this section, we calculated the Median, $1^{\text {st }}$ and $3^{\text {rd }}$ quartile and the maximum and minimum values for the values of each of the questions, shown in figure 5 below. The $\mathrm{X}$-axis values correspond to the number used for the question in the questionnaire.

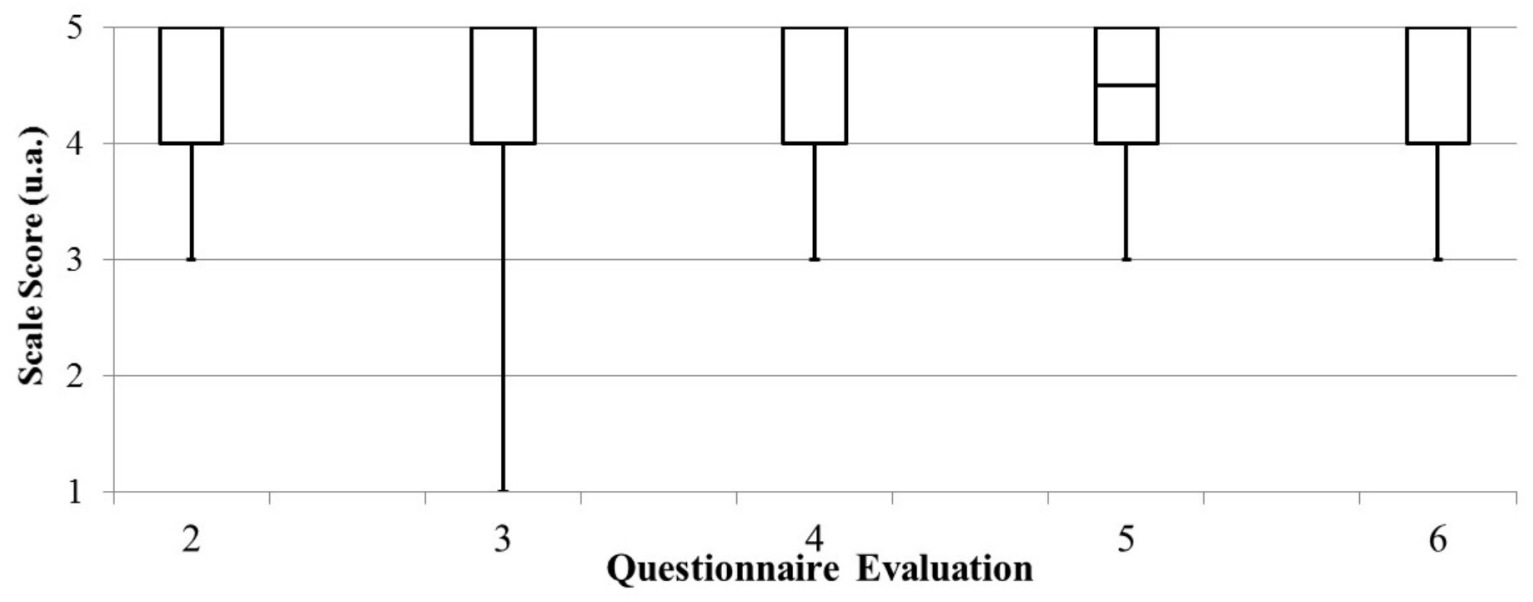

Figure 5: Median, 1st and 3rd quartile values and maximum and minimum values for the Questionnaire Evaluation itens.

Where: (2) Clarity of questions; (3) Relevance of questions; (4) Reliability of questions; (5) Importance of information; (6) Satisfaction with the questionnaire. Source: The author

Thus, by the median values of each of the evaluated items, it was verified that the proposed questionnaire met the expectations, being considered a very good instrument for this type of data collection.

\section{Discussion}

Several authors have shown, over the years, interest in investigating the DM of setters in volleyball. Such interest arises from the importance of these players to the performance of their teams. As previously highlighted, this is the athlete responsible in guiding the offensive dynamics of the team ${ }^{28}$, being considered the leader of each of the phases ${ }^{16}$. In these studies, the DM of the setters is represented in the literature under different terms, among which are: tactical determinants of setters ${ }^{29}$, tactical-strategical knowledge of setters ${ }^{17,30}$, tactical action of setters ${ }^{14}$, offensive organization of setters ${ }^{31}$, strategical knowledge of setters ${ }^{16}$, among others.
Regardless of the terms used, the aim of the authors has been to identify information (variables) that significantly interfere in this DM process, thus optimizing training processes and achieving better results. However, studies investigate a reduced number of variables, exceptions being the work done by Alfonso, Mesquita, Marcelino and Silva ${ }^{14}$ and Queiroga, Matias, Mesquita, Greco ${ }^{17}$. We also highlight the way in which the variables analyzed are defined, often based exclusively on the authors' experience. No study was found which began its investigations based on the opinion of experienced coaches in the modality.

Thus, the objective of this study was to build and validate a questionnaire which enabled the identification of information about the variables that play a role in the DM of setters. Taking into account the functional game structure proposed by Eom and Schutz ${ }^{19}$, the questionnaire was formulated to collect information regarding the work of setters during the AP's and CAP's. As seen, despite being composed of 55 questions, the questionnaire can be completed in a timely manner, not requiring, from the participants, very long periods 
of attention and focus, which in turn could make answering the questionnaire a tiresome task, with dubious answers. In addition to the time to answer the questionnaire, the coaches found the questions were formulated with important information, were clear, relevant and reliable. Generally, coaches were satisfied with the instrument both because it was relatively quick to finish, and its questions were relevant.

Based on the data obtained with the questionnaire, an important result to be highlighted was to verify that all information contained in the questionnaire, even with different proportions, may interfere with the DM process of the setters. Thus, in volleyball, the setter's DM might be dependent of the interaction of various technical and tactical factors ${ }^{32}$, and not just the individual capacity of the attacker ${ }^{14,16}$, psychological constraints ${ }^{14}$ or even physical factors, as highlighted by Challoumas and Artemiou ${ }^{33}$ who, in their studies, found a correlation between attack efficiency and anthropometric factors. In this sense, when investigating the DM of setters, authors should consider that it might be influenced by different, varied factors. As highlighted in the literature ${ }^{2,34,35}$, even minimal changes in factors involving the performance of a motor skill may influence it positively or negatively. In order to more broadly understand the phenomenon of DM, taking into account all the factors that surround the athlete, some authors have sought a more ecological analysis scale, in which the relationship between individual and environment is defined ${ }^{2,41}$.

Another point worth mentioning in the results concerns the differences found between the game processes. Most of the information present in the questionnaire, according to the coaches, influences the setters' DM process differently when considered in the AP or CAP. Only SP and LBA information influence the setters DM process in a similar way during PATs and CAP's. Such fact may be related to the independence of this information from movement, or successful execution of a skill; thus, the different characteristics that involve AP's and CAP's do not present themselves as intervening factors. The same reason may be related to a small difference of importance for the HA, BWP, ST, FCQ, IEP and OSL/LOA information.

The information that, according to the coaches, showed greater differences of importance for the DM process of the setters with regard to the AP's and CAP's were OBP, OBA, MHA, SZ, TNC, RZ, LDH and OST/OAT, where the largest difference found and the highest decrease in the classification was related to SZ. As for OST and OAT, the OAT, found during the CAPs, had a greater influence on the DM process of the setters than the OST found in the APs. The OBF and BE information, which appear sexclusively in the CAPs, influenced the DM process of the setters in an intermediate way, and OBF had greater influence than BE.

Regarding the classification of the information, it was verified that, for the coaches, the information most involved in the DM process of the setters, both in the APs and in the CAPs, relate to the quantity and which players may be activated during the setting and the behavior of the blockers of the opposing team. The number of players and the specific players available to the setter can increase the number of possible combinations, which would lead to an overload of unpredictable responses to the opposing team, as explained by Hick's Law ${ }^{41}$.

Another point is that, for coaches, setters must, always, act on the behavior and characteristics of the blockers of the opposing team. The identification of the blocking tactics of the opposing team, regarding the initial positioning, and the anticipation of the blockers, together with the identification of the BWP, is information of great relevance for the work of the setters. With this information, setters are able to reach the main goal of setting actions that, according to Alfonso, Mesquita, Marcelino and Silva ${ }^{14}$, should culminate in an action that causes difficulties on the blocking action of the opposing team, with the attackers facing weaker and/or poorly positioned blockers.

\section{Conclusion}

With the analysis of the results, it can be concluded that the questionnaire was a useful tool in the search of information regarding the DM of setters, and that such information might contribute to future studies. The identified information indicates that the DM process of the setters related to deciding where to set, is influenced not only by internal factors, i.e., those coming only from the player. Environmental and task factors, which are constantly changing during the game, also show great relevance. Such information should be considered by the authors when studying the DM process of setters.

It can also be verified that the different information interferes in the DM process of the setters differently during AP's and CAP's, which may be related to the distinct characteristics of each of the game processes. Although some information does not change or slightly change its importance among the processes, most of them show a decrease in importance for the setters' DM process.

With these results, coaches can use them as important information during training, in an attempt to optimize results. Researchers can use them to gain further insight into DM research in general, and more specifically, volleyball.

For future studies, more care should be taken regarding the use of the proposed questionnaire. In the present study, the collection was made with highly experienced coaches, however, there was no concern regarding an stratification by category or by the line of work, which can be considered a limitation of the study. Thus, questions pertaining to this stratification may be included in the questionnaire for future studies in order to better represent the results obtained. Therefore, future research can be done using the questionnaire in order to compare the opinion of coaches of various categories, active in teams of both genders, and to contrast this information between athletes with varied experiences.

A limitation of this study was sending the questionnarire via electronic means, emphasizing that, in future studies, this questionnaire can be applied in person with the coaches. 


\section{References}

1. Turvey MT, Shaw RE. in The Science of the Mind: 2001 and Beyond (eds. Solso RL, Massaro DW). New York, Oxford University Press, 1995; p. 144-169.

2. Araújo D, Davids K, Hristovski R. The ecological dynamics of decision making in sport. Psychol. Sport Exerc. 2006; 7: 653-676.

3. Vilar L, Araújo D, Davids K, Button C. The role of ecological dynamics in analysing performance in team sports. Sports Med. 2012; 42: 1-10.

4. Araújo D, Davids K, Chow JY, Passos P, Raab, M. The development of decision making skill in sport: an ecological dynamics perspective. In: Perspectives on Cognition and Action in Sport (eds. Araujo, D, Ripoll, H). Suffolk, Nova Science Publishers, 2009; p. 157-169.

5. Passos P, Araújo D, Davids K, Gouveia L, Serpa S, Milho J, et al. Interpersonal pattern dynamics and adaptive behavior in multiagent neurobiological systems: conceptual model and data. J. Mot. Behav. 2009; 41: 445-59.

6. Araújo, D. Tomada de Decisão no Desporto. 2006, Cruz Quebrada; FMH edições. p. 317.

7. Araújo D, Davids K, Bennett SJ, Button C, Chapman G. Emergence of Sport Skills under constraints. In Skill Acquisition in Sport: Research, Theory and Practice (eds. Williams AM, Hodges NJ). London, Routledge Taylor \& Francis Group; 2004. p. 409-433.

8. Araújo D, Davids K, Serpa S. An ecological approach to expertise effects in decision-making in a simulated sailing regatta. Psychol. Sport Exerc. 2005; 6: 671-692.

9. Domínguez AM, Álvarez FDV, García-González L, Arias AG, Arroyo, MPM. Intervención en la toma de decisiones en jugadores de voleibol en etapas de formación. Rev. Psicol. del Desporte. 2011; 20: 785-800.

10. García-González L, Araújo D, Carvalho J, del Villar F. Panorámica de las teorías y métodos de investigación en torno a la toma de decisiones en el tenis. Rev. Psicol. del Desporte. 2011; 20: 645-666.

11. Gaspar P, Ferreira JP, Pérez LMR. Tomadas de decisão no desporto: $\mathrm{O}$ seu ensino em jovens atletas. Rev. Mackenzie Educ. Física e Esporte. 2005; 4: 95-111.

12. Williams AM, Ward PA. Anticipation and Decision Making: exploring new horizons. In: Handbook of sport Psychology (eds. Tenenbaum G, Eklund, RC). New Jersey, John Wiley \& Sons, Inc; 2007. p. 203-223.

13. Afonso J, Mesquita IR, Marcelino R. O. Estudo de variáveis especificadoras da tomada de decisão, na organização do ataque, em voleibol feminino. Rev. Port. Ciências do desporto. 2008; 8: 137-147.

14. Alfonso J, Mesquita IR, Marcelino RO, Silva JA. Analysis of the setter's tactical action in high-performace women's volleyball. Kinesiology. 2010; 42: 82-89.

15. Denardi RA, Clavijo FAR, Oliveira, TAC de, Travassos B, Tani G, Corrêa UC. The volleyball setter's decision-making on attacking. Int. J. Perform. Anal. Sport. 2017; 8668: 1-

16. Mesquita IR, Graça AS. Probing the strategic knowledge of an elite volleyball setter - a case study. Int. J. Volleyb. Res. 2012; 5: 13-17.

17. Queiroga MA, Matias CJAS, Mesquita IR, Greco PJ. O conhecimento tático-estratégico dos levantadores integrantes das seleções brasileiras de voleibol. Fit. Perform. 2010; 9: 78-92.
18. Rocha CM. Análise das ações de ataque no voleibol masculino de alto nível. São Paulo. Dissertação [Mestrado em Educação Física] - Universidade de São Paulo; 2001.

19. Eom HJ Schutz RW. Statistical analyses of volleyball team performance. Res. Q. Exerc. Sport. 1992; 63: 11-8.

20. Günther H. Como Elaborar um Questionário. Laboratório Psicol. 2003, Série: Planejamento de Pesquisa nas Ciências Sociais: 1-15.

21. Avugos S, Köppen J, Czienskowski U, Raab M, Bar-Eli M. The "hot hand" reconsidered: A meta-analytic approach. Psychol. Sport Exerc. 2013; 14: 21-27.

22. Palao JM, Santos JA, Ureña A. The effect of the setter's position on the spike in volleyball. J. Hum. Mov. Stud. 2005.

23. Costa GDCT, Mesquita IR, Greco PJ, Ferreira NN, Moraes JC. Relação entre o tempo, o tipo e o efeito do ataque no voleibol masculino juvenil de alto nível competitivo. Rev. Bras. Cineantropometria e Desempenho Hum. 2010; 12: 428-434.

24. Rocha CM, Barbanti VJ. Uma análise dos fatores que influenciam o ataque no voleibol masculino de alto nível. Rev. Bras. Educ. Física e Esporte. 2004; 8: 303-314.

25. Franks IM, Mcgarry T. The science of match analysis. In: Science and Soccer (ed. Reilly T). London, Taylor \& Francis e-Library. 2003; P. 363-375.

26. Martins GA. Sobre Confiabilidade e Validade. Rev. Bras. Cestão. 2006; 8: 1-12.

27. Thomas JR, Nelson JK, Silverman SJ. Métodos de pesquisa em atividade física. Porto Alegre, Artmed; 2007.

28. Matias CJAS, Greco PJ. Desenvolvimento e validação do teste de conhecimento tático declarativo para o levantador de voleibol. Arq. em Mov. 2009; 5: 61,80.

29. Afonso J, Esteves F, Araújo,RM, Thomas L, Mesquita IR. Tactical determinants of setting zone in elite men's volleyball. J. Sport. Sci. Med. 2012; 64-70.

30. Matias CJADS, Greco PJ. A grelha do conhecimento tático-estratégico dos levantadores: estudo realizado com os campeões dos escalões de base e da Superliga de Voleibol. Cad. Educ. Física. 2010; 9: 29-40.

31. Matias CJADS, Greco PJ. Conhecimento tático-estratégico dos levantadores brasileiros campeões de voleibol: da formação ao alto nível. Rev. Bras. Educ. Física e Esporte. 2011; 25: 513-535.

32. Marcelino RO, Afonso J, Moraes JC, Mesquita IR. Determinants of attack players in high-level men's volleyball. Kinesiology. 2014; 46: 234-241.

33. Challoumas D, Artemiou A. Predictors of Attack Performance in High-level Male Volleyball Players. Int. J. Sports Physiol. Perform. 2018; p. 1-23.

34. Fajen BR, Riley MA, Turvey MT. Information, affordances, and the control of action in sport. Int. J. Sport Psychol. 2008; 40: 79-107.

35. Newell KM. Constraints on the development of coordination. In: Motor Development in Children: Aspects of Coordination and Control (eds. Whiting HTA, Wade MG). Amsterdam, Springer Netherlands - Nato Science Série D; 1986. p. 341-360.

36. Paulo A, Zaal FTJM, Fonseca S, Araújo D. Predicting Volleyball Serve-Reception. Front. Psychol. 2016; 7: 1694.

37. Barsingerhorn AD, Zaal FTJM, Poel HJ, Pepping G-J. Shaping decisions in volleyball: An ecological approach to decision-making in volleyball passing. Int. J. Sport Psychol. 2013; 44: 197-214. 
38. Jäger JM, Schöllhorn WI. Situation-orientated recognition of tactical patterns in volleyball. J. Sports Sci. 2007; 25: 1345-53.

39. McPherson SL, Kernodle MW. in Expert performance in sports: advances in research on sport expertise (eds. Starkes, J. L. \& Ericsson, K. A.) 2003, Human Kinetics Publishers Inc. p. 137-167.

40. Passos P, Araújo D, Davids K, Gouveia L, Milho J, Serpa S. Information-governing dynamics of attacker-defender interactions in youth rugby union. J. Sports Sci. 2008; 26: 1421-9.

41. Davids k. Ecological dynamics in analysis of performance in team sport. In: Balagué N, Torrents C, Vilanova A, et al. (Orgs.); 18th annual Congress of the European College of Sport Science. v. 20, p.330, 2013. Barcelona - Spain: National Institute of Physical Education of Catalonia (INEFC).

42. Hick WE. On the rate of gain of information. Q. J. Exp. Psychol. 1952; 4: 11-26.

\section{Corresponding author}

Fábio Luis Bordini

Colégio Militar de Curitiba, Coordenação de Educação Física. Praça Conselheiro Thomaz Coelho, 01 CEP: 82800-030 Tarumã, Curitiba, Paraná.

Email: flbordini@gmail.com

Manuscript received on June 14, 2018

Manuscript accepted on December 4, 2018

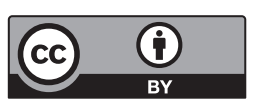

Motriz. The Journal of Physical Education. UNESP. Rio Claro, SP, Brazil - eISSN: 1980-6574 - under a license Creative Commons - Version 4.0 